\title{
Application of multi energy optimal scheduling in intelligent energy management and control platform
}

\author{
Jing Nie ${ }^{1, *}$, Xiaoguang $\mathrm{Qi}^{1}$,Yan Song ${ }^{1}$, Nan $\mathrm{Xu}^{1}$, Yongli Wang ${ }^{2}$, Huanran Dong ${ }^{2}$ \\ ${ }^{1}$ State Grid Hebei Electric Power Co., LTD, Hebei, 050000, China \\ ${ }^{2}$ North China Electric Power University, Beijing, 102206, China
}

\begin{abstract}
This paper analyzes the physical architecture and functional requirements of the regional smart energy management and control platform, and points out the key technologies applied in the platform development. Based on the consideration of multi energy balance, diversified user demands and changeable scenarios, the day ahead economic optimal scheduling model of smart park is established, and the optimal scheduling operation results are given.
\end{abstract}

\section{Introduction}

Energy is the basis of human survival and development. Improving energy utilization rate, developing new energy and strengthening the utilization of renewable energy are the inevitable choice to solve the contradiction between the increasing energy demand and the shortage of resource supply and demand[1-3]. The concept of multi energy complementarity breaks the bottleneck of independent traditional energy supply and realizes the collaborative optimization of various energy forms.

At present, the research on multi energy complementary system mostly aims at improving the constraints of optimal operation scheduling or the algorithm of solving optimization model, and the research on uncertain factors is just in the beginning. In reference [4], considering the randomness of photovoltaic power generation and wind power generation, based on the framework of chance constrained programming, a micro grid economic operation model is proposed, and the opportunity constraints in the optimization object model are transformed into equivalent classes of deterministic constraints by using sequence operation theory; In reference [5], the source load is regarded as a fuzzy variable and represented by trapezoidal and triangular parameters. Based on the credibility theory, the fuzzy chance constraint is constructed, and the equivalence of the chance constraint is transformed into a clear equivalence class; In reference [6], the load distribution characteristics of CCHP system are described by using the weighted sum method of normal distribution, and a stochastic fuzzy modeling method of load is proposed to verify the randomness and fuzziness of load;

This paper analyzes the physical architecture and functional requirements of the regional smart energy management and control platform, and points out the key technologies applied in the platform development. Based on the consideration of multi energy balance, diversified user demands and changeable scenarios, the day ahead economic optimal scheduling model of smart park is established, and the optimal scheduling operation results are given.

\section{Multi energy optimal scheduling model}

The intelligent energy system of the park includes three energy forms: heat, electricity and gas, with the characteristics of various load types and abundant energy supply equipment. In the MATLAB environment, a variety of energy supply equipment (including electric energy storage) is modeled. CPLEX is used to solve the mixed integer programming problem, and the day ahead economic optimal scheduling model of intelligent energy system is established. Based on the system energy supply architecture and boundary conditions of a distributed energy station project in an industrial park, a day ahead economic optimal scheduling model of smart park system is established. The input of the model includes the types and capacity of cogeneration units, gas-fired boilers, batteries, photovoltaic, wind turbines, as well as the purchase price, electric heating load, wind speed and light intensity.

Based on the mathematical model of various equipment, considering the influence of electricity purchase price, the objective function of economic optimization of the system is established. By solving the economic optimization model, the purpose of making reasonable operation strategy is achieved. It is assumed that the equipment output of the system is a continuous variable and there is no fault leading to equipment outage during the optimal operation.

\section{Constraints and objective functions}

* Corresponding author's e-mail: szsssxxysh@163.com 


\subsection{Objective function}

The objective function of minimizing the daily operation cost of smart energy system is as follows:

$$
\min C_{o s t}=\min \left(C_{\text {grid }}+C_{\text {fuel }}\right)
$$

In the formula: $C_{\text {grid }}$ is the power cost interacting with the power grid; $C_{\text {fuel }}$ is the fuel cost.

$$
C_{\text {fuel }}=\sum_{t} c_{b} P_{b}(t)-c_{s} P_{s}(t)
$$

In the formula: $P_{b}(t)$ and $c_{b}$ represent the power and price of electricity purchased to the grid during $\mathrm{t}$ period; $P_{s}(t)$ and $c_{s}$ represent the power and price of electricity sold to the grid during t period.

\subsection{Constraints}

(1) Equipment output constraints

In order to ensure that the cogeneration system operates in a safe range, the equipment output is limited to a certain range, namely:

$$
P_{\min }^{k} \leq P_{k} \leq P_{\max }^{k}
$$

In the formula: $P_{k}$ represents the output of the $\mathrm{K}$ group equipment (including gas turbine (GT), gas fired boiler (GB), Electric refrigerator (EC), absorption chiller (AC) and photovoltaic (PV)), and $P_{\max }^{k}$ and $P_{\text {min }}^{k}$ represent the upper and lower limits of the output of the $\mathrm{K}$ group equipment respectively.

(2) Interactive power constraints with power grid

$$
\left\{\begin{array}{l}
P_{b}^{\min } \leq P_{b} \leq P_{b}^{\max } \\
P_{s}^{\min } \leq P_{s} \leq P_{s}^{\max }
\end{array}\right.
$$

In the formula,: $P_{b}^{\max }$ and $P_{b}^{\min }$ represent the upper and lower limits of the power to be purchased, and $P_{s}^{\max }$ and $P_{s}^{\min }$ to be the upper and lower limits of the power to be sold.

(3) Power balance constraints

The sum of gas turbine power generation, photovoltaic cell power generation and electricity purchased from the grid is equal to the power load demand, electric refrigerator power consumption and electricity sales to the grid.

$$
P_{b}+P_{G T}+P_{P V}=P_{E L E}+P_{E C}+P_{s}
$$

(4) Heat balance constraint

When the heat storage tank (TST) is in the heat release state, the sum of the waste heat power recovered by the gas turbine (GT), the heat power generated by the gas boiler (GB) and the heat release power of the TST is greater than or equal to the heat power consumed by the absorption chiller (AC) and the heat exchanger (EX); When TST is in heat storage state, the sum of waste heat power recovered by GT and thermal power generated by
GB is greater than or equal to the thermal power consumed by $\mathrm{AC}$ and ex and thermal storage power of TST.

$$
\left\{\begin{array}{cc}
Q_{H R S}+Q_{G B}+Q_{d i s c h} \bullet \eta_{T S T}^{\text {disch }} \geq & \text {,TST } \\
Q_{A C} / C O P_{A C}+Q_{E X} / C O P_{E X} & \text { heat } \\
Q_{H R S}+Q_{G B}-Q_{c h} \bullet \eta_{T S T}^{c h} \geq & \text { storage } \\
C O P_{A C}+Q_{E X} / C O P_{E X} & \text { thermic }
\end{array}\right.
$$

In the formula: $Q_{H R S}$ represents the heat recovered by GT; $Q_{\text {disch and }} \eta_{T S T}^{\text {disch }}$ represent the heat release and corresponding heat release efficiency of TST; $Q_{c h}$ and $\eta_{T S T}^{c h}$ represent the heat storage capacity and corresponding heat storage efficiency of TST.

(5) Cold balance constraint

The capacity of the chiller should be equal to or greater than that of the absorption chiller.

$$
Q_{A C}+Q_{E C} \geq Q_{c l}
$$

(6) Operation constraints of regenerator

Due to the existence of two states of heat storage and heat release, the constraints of heat storage tank are slightly more complex than those of other equipment:

$$
\left\{\begin{array}{c}
Q_{c h}^{\min } \leq Q_{c h} \leq Q_{c h}^{\max } \\
Q_{d i s c h}^{\min } \leq Q_{d i s c h} \leq Q_{d i s c h}^{\max } \\
W_{h}^{\min } \leq W_{h} \leq W_{h}^{\max } \\
W_{h}^{\min }-W_{h}^{0} \leq \sum_{t=1}^{T} \eta_{T S T}^{c h} Q_{c h}+Q_{d i s c h} / \eta_{T S T}^{\text {disch }} \\
\leq W_{h}^{\max }-W_{h}^{0}
\end{array}\right.
$$

In the formula, $Q_{c h}^{\max }$ and $Q_{c h}^{\min }$ are the upper and lower limits of the heat storage power of the heat storage tank, $Q_{\text {disch }}^{\max }$ and $Q_{\text {disch }}^{\min }$ are the upper and lower limits of the heat release power of the heat storage tank, $W_{h}^{\max }$ and $W_{h}^{\text {min }}$ are the upper and lower limits of the storage tank capacity, and $W_{h}^{0}$ is the initial capacity of the heat storage tank.

\section{Simulation Result}

The system adopts the principle of self use and grid connection without grid connection. The main equipment includes gas turbine, waste heat boiler, gas boiler, battery, distributed photovoltaic power generation system and distributed photovoltaic power generation system. The system exchanges power with the power grid through a public connection point. When the power supply is insufficient, the system purchases electricity from the State Grid, and charges the energy storage 
system when the system is surplus. The energy storage battery is lithium iron phosphate battery pack.

The natural gas price and electricity price in different seasons and periods in this area are shown in Table 1. The relevant parameters in the example are shown in Table 2 and table 3.

Table 1. Electricity price for park purchase (peak, low and normal period).

\begin{tabular}{ccc}
\hline Price type & $\begin{array}{c}\text { Price/ } \\
\text { (yuan/kWh) }\end{array}$ & Time slot \\
\hline capacity & 0 & \\
payment & & \\
Power tariff & 0 & $23: 00-7: 00$ \\
\hline Electricity price & 0.3746 & $11: 00-19: 00$ \\
(high) & 0.7492 & $23: 00-7: 00$ \\
& 1.1238 & $11: 00-19: 00$ \\
\hline Electricity price & 0.4102 & $23: 00-7: 00$ \\
(low) & 0.8203 & $11: 00-19: 00$ \\
\hline \multirow{2}{*}{ Electricity price } & 1.2305 & $7: 00-11: 00,19: 00-23: 00$ \\
(normal) & 0.3943 & \\
\hline natural gas & 0.7886 & \\
\hline
\end{tabular}

Table 2. Functional equipment parameters

\begin{tabular}{cccc}
\hline Equipment & $\begin{array}{c}\text { Unit } \\
\text { quantity } \\
\text { / set }\end{array}$ & Parameter & $\begin{array}{c}\text { Power } \\
\text { /MW }\end{array}$ \\
\hline $\begin{array}{c}\text { Gas turbine }+ \\
\text { waste heat } \\
\text { boiler }\end{array}$ & 2 & $\begin{array}{c}\text { Rated power generation } \\
\text { (heating) } \\
\text { Minimum generation } \\
\text { (heating) }\end{array}$ & $\begin{array}{c}14.4 \\
3.9\end{array}$ \\
\hline Gas fired boiler & 2 & Rated heating & 14 \\
\hline photovoltaic & & Minimum heating & 4.2 \\
\hline Wind power & & Rated power generation & 3 \\
\hline Energy storage & Rated power generation & 0.3 \\
\hline
\end{tabular}

Table 3. Parameters of energy storage equipment.

\begin{tabular}{ccccc}
\hline $\begin{array}{c}\text { Available } \\
\text { capacity } \\
/ \mathbf{k W}\end{array}$ & $\begin{array}{c}\text { Maximum } \\
\text { charging } \\
\text { power } \\
/ \mathbf{k W}\end{array}$ & $\begin{array}{c}\text { Charge and } \\
\text { discharge cost } \\
/ \text { (times/yuan) }\end{array}$ & DOD & $\begin{array}{c}\text { Initial } \\
\text { state of } \\
\text { charge }\end{array}$ \\
\hline 2857 & 500 & 1300 & 0.7 & 0.3 \\
\hline
\end{tabular}

By solving the economic optimal scheduling model, the following results are obtained :

The system starts charging of energy storage system from 0:00 to 7:00 during the low electricity price period, and the gas turbine unit starts to work to meet the power load demand of the system; the photovoltaic system enters the generation time from 10:00 to 17:00, and purchases power from the State Grid from 0:00 to 24:00 to make up for the insufficient power generation of the system. At the same time, the energy storage system discharges to the system to earn the peak valley price difference.

The steam heat load demand of the system is provided by waste heat boiler and gas boiler. During 0:00-7:00, the gas turbine is in low load rate operation, and in 8:00-21:00, the gas turbine is in high load rate operation. At the same time, in order to meet the peak load demand, the No.1 gas-fired boiler is started at 16:00-18:00.

To sum up, the optimized energy supply scheme can meet all the energy demand of the energy system of the smart Park, and there is no wind, light and heat abandonment in the system. Table 4 shows the comparison of daily operation cost before and after system optimization.
Table 4. System daily operation cost under different scheduling strategies.

\begin{tabular}{cc}
\hline Control strategy & $\begin{array}{c}\text { Daily operation cost } \\
\text { / yuan }\end{array}$ \\
\hline $\begin{array}{c}\text { After optimization } \\
\text { Not optimized (gas } \\
\text { turbine + gas fired boiler } \\
\text { only) }\end{array}$ & 220947.21 \\
\hline
\end{tabular}

Among them, the optimized system adopts the proposed dispatching strategy, and the daily operation cost is 220947.21 yuan; the UN optimized system refers to that all the electrical loads of the system are connected by the public power grid, and the heat load is provided by gas-fired units and gas-fired boilers, and the daily operation cost is 328562.84 yuan. The operation cost of the system can be reduced by $32.7 \%$ after using the optimal scheduling strategy. Therefore, the daily operation cost of the system can be significantly reduced through the operation mode and output of each energy supply equipment in the smart energy system, and the economic optimal operation of the smart energy system can be realized.

\section{Conclusions}

The simulation results show that the multi energy optimization scheduling function can significantly reduce the daily operation cost of the system. As the core function of smart energy system, multi-energy optimal scheduling can effectively improve the energy utilization efficiency of the system, promote the optimal allocation of resources and improve the operation economy.

The construction of smart energy management and control platform should first build a multi energy complementary smart energy infrastructure network, monitor and upload the operation, environment and basic data of the smart energy system, so as to realize data integration and data transmission; then establish the "ubiquitous energy Internet of things" with extensive participation; finally, realize the unification of business and scheme by cultivating diversified new energy business models.

\section{Acknowledgment}

The athors would like to thank the support of the project"Science and Technology Foundation of State Grid Corporation of China (SGHEJY00JJJS2000064)".

\section{References}

1. Jia Hongjie, Mu Yunfei, Yu Xiaodan. Thought about the Integrated Energy System in China[J]. Electric Power Construction, 2015, 36( 1) :16-25.

2. Sun Hongbing, Guo Qinglai, Pan Shaoguang. Energu Internet: Concept, Architecture and Frontier Outlook[J]. Automation of ElectricPower Systems, 2015, 39( 19) : 1-8.

3. Feng Qingdong, A Review of the State of the Art of Distributed Generation and Micro Grid[J], Electrical 
Measurement \& Instrumentation, 2013, 50(2) : 5459.

4. Jin Peng,Ai Xin,Xu Jiajia, An Economic Operation Model for Isolated Microgrid based on Sequence Operation Theory $[\mathrm{J}]$, Proceedings of the CSEE, 2012, 32( 25) : 52-59.

5. Xiong Hu,Xiang Tieyuan,Chen Hongkun, Research of fuzzy chance constrained unit commitment containing large-scale intermittent power[J], Proceedings of CSEE, 2013, 33( 13) : 36-44.

6. Ma R ui,Li Wenye,Li Heng,et al, Random Fuzzy Model for Load of Distributed Combined Cooling,Heating and Power System[J], Automationof Electric Power Systems,2016,40( 15) : 53-58. 